\title{
Moderate intensity physical activity prevents increased blood glucose concentrations, fat pad deposition and cardiac action potential prolongation following diet-induced obesity in a juvenile-adolescent rat model
}

\author{
Alannah van Waveren ${ }^{1 *}$, Mitch J Duncan ${ }^{2}$, Fiona R Coulson ${ }^{3}$ and Andrew Fenning ${ }^{1,3}$
}

\begin{abstract}
Background: Both obesity and a lack of physical activity have been associated with an elevated risk of cardiovascular disease (CVD). The incidence of obesity is increasing, especially in juvenile-adolescents. While there is limited research examining the chronic effects of obesity in adolescent humans and animal models of this condition, little is also known concerning how moderate physical activity might prevent or attenuate secondary cardiovascular complications induced by obesity during adolescence. We investigated the effects of diet-induced obesity (consisting of a high-fat, high-carbohydrate diet (HFHC)) on biometric indices, vascular and airway function, cardiovascular function, systemic oxidative stress and markers of inflammation in a juvenile-adolescent rodent model. Four groups were used: control (CON), physical activity (PA) treated, HFHC and HFHC + PA ( $n=16$ per group). HFHC feeding started at 4 weeks of age for a period of 12 weeks. Physical activity treatment was initiated (PA and HFHC + PA groups) when the animals were 8 weeks of age, for 8 weeks.
\end{abstract}

Results: Physical activity in juvenile-adolescent healthy rats showed no change in comparison to the CON group in all experimental parameters except for increases in lipid peroxidation, decreases in inflammatory cytokines, improvements in vascular reactivity and decreased atrial responses to positive chronotropic agents. The HFHC animals were mildly hyperglycemic, hypertensive, displayed renal hypertrophy and showed increased retroperitoneal fat pad deposition compared to the CON group. HFHC + PA rats were also hypertensive, however showed improvements in cardiac electrophysiology, body weight, fat pad deposition and inflammatory signaling, in comparison to the HFHC fed rats and CON animals.

Conclusion: In conclusion, in a juvenile-adolescent animal model of diet-induced obesity engagement in physical activity is beneficial in reducing the inflammatory effects of obesity.

Keywords: Western obese diets, Juvenile obesity, Metabolic syndrome, Physical activity, Hypertension, Oxidative stress, Inflammation, Vascular reactivity, Cardiac arrhythmia

\footnotetext{
* Correspondence: a.somerfield@cqu.edu.au

${ }^{1}$ Central Queensland University, Institute of Health and Social Science

Research, Rockhampton, Queensland 4702, Australia

Full list of author information is available at the end of the article
} 


\section{Background}

In recent decades the prevalence of overweight youth and obesity in humans has increased [1,2]. Juvenile onset obesity has been associated with adverse changes in cardiovascular risk in both animals and humans ([3-5]). Animal studies show that cardiorespiratory function and blood pressure are adversely altered following juvenileonset obesity in comparison to older models of obesity [6-8]. In addition, following high fat feeding that induced obesity; blood pressure in the young rats became significantly elevated $[6,8]$. This increase resulted in a more advanced metabolic syndrome in contrast to the older animals fed a similar diet, over a similar time period $[6,8]$. Obesity has also been shown to adversely alter respiratory physiology, including a heightened demand for ventilation, diminished respiratory compliance, elevated work of breathing and respiratory muscle inefficiency [9-11].

Adipose tissue plays a key role in the secretion of many pro-inflammatory cytokines [12-14] with higher body fat deposits promoting an excess secretion of adipokines [15]. These released adipokines promote a raft of systemic effects including enhanced appetite, insulin resistance, altered bone metabolism, altered endocrine and reproductive function, decreases in pulmonary function and an increased risk of CVD [12-14,16,17]. Therefore, a reduction in adipose tissue generates an anti-inflammatory state, which reduces CVD risk. Reduction in adipose tissue is typically achieved by increases in physical activity, improved dietary habits or a combination of both.

Physical activity has been defined as by the World Health Organization as any bodily movement produced by skeletal muscles that requires energy expenditure [18]. Exercise, also defined by the World Health Organization, is a subcategory of physical activity defined as being planned or structured and can be repetitive [18]. Exercise is assumed to have a final objective being the improvement or maintenance of physical fitness [18]. Physical activity in daily life includes exercise and can be categorized into other activities which involve bodily movement and are done as part of playing, occupation, active transportation, household chores and sports [18].

The health benefits of regular physical activity occur via many pathways including improved regulation of metabolic irregularities, blood pressure, glucose clearance, myocardial energetics, coronary artery diameter and vasomotor tone $[19,20]$. Physical activity has also been found to have anti-inflammatory effects linked to a reduction in risk of atherosclerosis and CVD [19] through decreases in the release of pro-inflammatory cytokines [21-23]. Whereas, weight-loss associated with physical activity confers a significant health benefit and has been shown to improve endothelial dysfunction and decrease systemic inflammation [24]. Studies in rodents showed that swimming for 2 hours/day, 5 days/week for 6 weeks reduced insulin resistance induced via a high fat diet [25]. Similarly, treadmill-running studies using rats, where animals completed 13 weeks of treadmill-running 5 days/week demonstrated that physical activity decreased hypertension caused by diet-induced obesity [3]. Whilst these studies have demonstrated that physical activity can reduce markers of cardiometabolic, CVD risk following diet-induced obesity in adult animal models, it is unknown how physical activity impacts CVD risk in youth.

The aims of this study were to 1) examine if diet-induced obesity causes metabolic syndrome and associated secondary CVD complications such as elevated blood pressure and blood glucose, depressed cardiovascular and respiratory function and enhanced systemic inflammation and oxidative stress in a juvenile-adolescent rat model and 2) to examine if physical activity can reduce these adverse changes.

\section{Methods}

Animals and animal care

All experimental procedures were approved by the CQUniversity Animal Ethics Research Committee (approval A10/11-265) and were conducted in accordance with the National Health and Medical Research Council (NHMRC) guidelines. Male Wistar rats were randomized into one of four experimental groups: 1) control (CON), 2) physical activity (PA), 3) high fat/high carbohydrate (HFHC) and 4) high fat/high carbohydrate combined with physical activity $(\mathrm{HFHC}+\mathrm{PA})$. Animals were started treatment at the juvenile age of 4 weeks $[26,27]$. HFHC was initiated at 4 weeks of age for a period of 12 weeks. Physical activity was initiated (PA and HFHC + PA) when the animals reached 8 weeks of age for a period of 8 weeks. All animals were euthanized at 16 weeks of age. CON and PA animals were fed standardized rat and mouse nuts (Norco Stockfeeds; South Lismore, NSW, Australia) and were exposed to room air.

\section{Physical activity protocol}

Groups subjected to physical activity (PA and HFHC + $\mathrm{PA})$, performed 30 minutes of moderate intensity exercise per day, five days per week for 8 weeks. This daily duration and intensity is consistent with the level of physical activity considered to confer health benefits in humans $[28,29]$. Studies have shown that a moderate intensity of physical activity for the rodent model is equivalent to $0.8 \mathrm{~km} /$ hour on a modified treadmill (AccuScan Instruments, Columbus, Ohio, USA), and is sufficient to induce physiological adaptations in cardiovascular function and biochemical parameters [30,31]. HFHC and CON groups were not subjected to physical activity, however where exposed to the same condition inside the treadmill unit. 


\section{HFHC diet-induced obesity model}

A modified HFHC diet [32,33] was prepared by Specialty Feeds (Glen Forrest, WA, Australia) and consisted of $45.3 \%$ digestible energy from lipids and 34.3\% from carbohydrates. The HFHC diet pellets contained casein $(233 \mathrm{~g} / \mathrm{kg})$, fructose $(175 \mathrm{~g} / \mathrm{kg})$, lard $(207 \mathrm{~g} / \mathrm{kg})$, soya bean oil $(29 \mathrm{~g} / \mathrm{kg})$, cellulose $(58 \mathrm{~g} / \mathrm{kg})$, wheat starch $(118 \mathrm{~g} / \mathrm{kg})$, dextrinized starch $(117 \mathrm{~g} / \mathrm{kg})$, DL methionine $(3.5 \mathrm{~g} / \mathrm{kg})$, calcium carbonate $(6.4 \mathrm{~g} . \mathrm{kg})$, sodium chloride $(2.6 \mathrm{~g} / \mathrm{kg})$, AIN93 trace mineral $(1.6 \mathrm{~g} / \mathrm{kg})$, potassium citrate $(19.2 \mathrm{~g} / \mathrm{kg})$, dicalcium phosphate $(15.1 \mathrm{~g} / \mathrm{kg})$, potassium sulphate $(1.6 \mathrm{~g} / \mathrm{kg})$, choline chloride $75 \%(1.3 \mathrm{~g} / \mathrm{kg})$ and AIN93 vitamins (12 g). Digestible energy was calculated at $19.5 \mathrm{MJ} / \mathrm{kg}$. The $\mathrm{CON}$ and PA did not receive the modified HFHC diet but standard rat chow. $\mathrm{kJ}$ consumption was calculated by weighing food and water intake daily. The consumption was then averaged based on the number of rats present in each cage and multiplied by $\mathrm{kJ}$ content in the food or water that was eaten.

\section{Body mass, heart rate and systolic blood pressure}

Systolic blood pressure and heart rate readings were taken 0, 4, 8 and 12 weeks. Systolic blood pressure and heart rate were measured via tail cuff plethysmography as outlined previously [34]. Body mass was measured weekly for all groups.

\section{Terminal assessments}

At completion of the 12-week treatment regime, all rats were euthanized using a $0.2 \mathrm{ml} / \mathrm{kg}$ i.p. injection of sodium pentobarbitone $(375 \mathrm{mg} / \mathrm{ml})$. Following euthanasia, the abdominal and chest cavities were opened and a $5 \mathrm{~mL}$ blood sample was collected from the abdominal vena cava. Internal organs including the heart, kidneys, liver, spleen and fat pads were removed and weighed.

\section{Glucose, 4-HNE, NO, IL-6 and IL-1B}

Blood glucose concentrations for each group were measured immediately following euthanasia using a blood glucose monitor (Medisense, Abbott Laboratories) and reported in $\mathrm{mmol} / \mathrm{L}$. All other biochemical measurements were performed using serum prepared from whole blood collected in a serum separator tube and allowed to clot before being centrifuged. Samples were then centrifuged for ten minutes at $14000 \mathrm{rpm}$ and the supernatant removed and stored at $-80^{\circ} \mathrm{C}$ to prevent sample degradation. To assess 4-hydroxynonenal (4-HNE) levels for each animal, serum samples were used in conjunction with a Cell Biolabs' Oxiselect ${ }^{\mathrm{Tm}}$ HNE adduct ELISA kit (Catalog Number STA-338). Nitric Oxide (NO) levels were assessed using a NO (total) Detection Kit (Catalog Number ADI-917-020). Assessments of serum interleukin-1 $\beta$ (IL-1 $\beta$ ) concentrations were made through the use of a R\&D Systems Quantikine Rat IL-1 $\beta /$ IL-1 F2 Immunoassay
(Catalog Number RLB00) with serum interleukin-6 (IL-6) concentrations determined through the use of R\&D Systems Quantikine Rat IL-6 Immunoassay (Catalog Number R6000B).

\section{Vascular reactivity in isolated tissues}

Thoracic aortic rings isolated from each rat were cleared of any fat and connective tissue before being suspended in $25 \mathrm{~mL}$ organ baths stabilized at $37^{\circ} \mathrm{C}$ with a continuously supplied with carbogen $\left(5 \% \mathrm{CO}_{2}\right.$ and $\left.95 \% \mathrm{O}_{2}\right)$ gas bubbled through tyrodes solution $(\mathrm{NaCl} 136.9, \mathrm{KCl} 5.4$, $\mathrm{MgCl}_{2}$ 1.05, $\mathrm{NaH}_{2} \mathrm{PO}_{4}$ 0.42, $\mathrm{NaHCO}_{3}$ 22.6, $\mathrm{CaCl}_{2}$ 1.8, glucose 5.5, ascorbic acid 0.28, EDTA 0.1 all in $\mathrm{mM}$ ). Each segment of thoracic aorta had a pre-set resting tension of $10 \mathrm{mN}$ and following a thirty minute equilibration period, cumulative concentration response curves (CRC) to noradrenaline (NA), acetylcholine (ACh) (NA pre-contraction) and sodium nitroprusside (Nano) (NA pre-contraction) were established with any fluctuation to the preset tension recorded using (Grass FT03) transducers connected to Chart software (21). Vascular reactivity in isolated pulmonary arteries was assessed using a 4-bath wire-myograph system (Danish Myograph Technologies, Denmark). Pulmonary arteries were dissected from the base of the heart and threaded with $40 \mu \mathrm{m}$ stainless steel wire while bathed in cold Tyrodes buffer and gassed with carbogen before being transferred to the myograph chambers at $37^{\circ} \mathrm{C}$. Once the pulmonary tissues had equilibrated for 20 minutes they were normalized using inbuilt normalization protocols of LabChart Pro 7 software (ADInstruments). Following successful normalization, tissues were rested at pre-load tension $10 \mathrm{mN}$, for 20 minutes before being contracted with $10 \mathrm{mM} \mathrm{KCL}$ and relaxed with a $1 \mathrm{e}-5 \mathrm{M}$ concentration of ACh. The pulmonary arteries were washed regularly for 30 minutes with fresh buffer solution before the commencement of the same CRC's to the thoracic aortic rings.

\section{Assessment of cardiac electrophysiological changes}

The papillary muscle was excised from the left ventricle and a stainless steel hook inserted through the superior end. The papillary muscle was then placed between two platinum electrodes in a $1.0 \mathrm{~mL}$ experimental chamber filled with Tyrodes physiological salt solution $\left(37^{\circ} \mathrm{C}\right.$; aerated with carbogen) and fixed into position with a stainless steel pin (21). The papillary muscle was then slowly stretched to a maximum pre-load $(5 \mathrm{mN})$ and then was then stimulated using a Grass SD-9 stimulator and contractions were induced at $1 \mathrm{~Hz}$, with a pulse width of $0.5 \mathrm{msec}$ and stimulus strength $20 \%$ above threshold. After a five-minute equilibration period, the papillary muscle was then impaled by a glass electrode filled with potassium chloride $1 \mathrm{M}$ (filamented borosilicate glass, 
outer diameter $1.5 \mathrm{~mm}$, tip resistance of 5-15 $\mathrm{m} \Omega$ when filled with $3 \mathrm{M} \mathrm{KCL}$ ), using a silver/silver chloride reference electrode. The electrical activity, which was recorded in $\mathrm{mV}$, of a cell was recorded following a further 25 minute equilibration period with a Cyto 721 electrometer was connected to an ADInstruments (Chart 7) recording system.

\section{Assessment of pacemaker changes}

The right atria were isolated from each rat and were cleared of any fat and connective tissue was removed before being suspended in $25 \mathrm{~mL}$ organ baths stabilized at $37^{\circ} \mathrm{C}$, filled with Tyrodes physiological salt solution (aerated with carbogen). Each atrium had a thirty-minute equilibration period, then cumulative concentration response curves (CRC) to isoprenaline (ISO) and calcium chloride $(\mathrm{CaCl})$ were added with any fluctuation to mediate rate response of recorded using (Grass FT03) transducers connected to Chart software.

\section{Assessment of airways function in isolated sections of trachea and bronchioles}

Trachea rings isolated from each rat were cleared of any fat and connective tissue before being suspended in $25 \mathrm{~mL}$ organ baths [35] stabilized at $37^{\circ} \mathrm{C}$ supplied with carbogen gas bubbled through modified $\mathrm{KHB}(\mathrm{NaCl}$ 119.1, $\mathrm{KCl} 4.75, \mathrm{MgSO}_{4} 1.19, \mathrm{KH}_{2} \mathrm{PO}_{4} 1.19, \mathrm{NaHCO}_{3}$ 25.0, glucose 11.0 and $\mathrm{CaCl}_{2} 2.16$ all in $\mathrm{mM}$ ) with added propranolol to replicate biological parameters. Each segment of trachea had a preset resting tension of $1 \mathrm{~g}$ and following a 30-minute equilibration period, CRC to carbachol (CAR), 5-hydroxytryptamide (5-HT) and isoprenaline
(ISO) were completed. Pulmonary responses in isolated bronchioles were assessed via a 4-bath wire-myograph system (Danish Myograph Technologies, Denmark). Second generation bronchioles were dissected from the lungs and threaded with $40 \mu \mathrm{m}$ stainless steel wire while bathed in cold $\left(10^{\circ} \mathrm{C}\right)$ Krebs-Henseleit buffer and gassed with carbogen before being transferred to the myograph chambers at $37^{\circ} \mathrm{C}$. Equilibration and normalization procedures were kept consistent with the pulmonary artery preparations. CRC were performed using 5-HT, ACh and ISO (ACh pre-contraction).

\section{Drugs and chemicals}

All drugs used in this study (NA, ACh, CAR, 5-HT, ISO and $\mathrm{NaNO}$ ) were purchased from the Sigma Chemical Company, St Louis MO, USA. Serial dilutions of the drugs were produced using distilled water.

\section{Statistical analysis}

Data is expressed as mean \pm standard error mean (SEM). Statistical analysis was performed using two-way analysis of variance (ANOVA) and students t-test where appropriate. Results were considered significant when $\mathrm{P}<$ 0.05 with analysis carried out using Graphpad Prism v5 (GraphPad Software La Jolla, CA 92037 USA).

\section{Results}

\section{Responses following PA}

No significant changes were observed in body mass in comparison to age- matched controls. Similar results were found in the fat pads and organ masses (Table 1).

Table 1 Systemic parameters in the four intervention groups

\begin{tabular}{|c|c|c|c|c|}
\hline & CON & PA & HFHC & $\mathrm{HFHC}+\mathrm{PA}$ \\
\hline Body weight (g) & $444.8 \pm 7.6$ & $465.5 \pm 8.9$ & $441.1 \pm 9.0$ & $422.9 \pm 8.0^{\dagger}$ \\
\hline Retroperitoneal (g) & $7.8 \pm 1.1$ & $7.9 \pm 0.6$ & $12.6 \pm 1.2^{* \dagger}$ & $9.0 \pm 0.7$ \\
\hline Subcutaneous (g) & $8.3 \pm 1.0$ & $8.5 \pm 0.7$ & $10.1 \pm 0.6$ & $8.9 \pm 1.3$ \\
\hline Epididymal (g) & $8.5 \pm 1.0$ & $6.2 \pm 0.3$ & $7.6 \pm 0.7$ & $7.8 \pm 0.5$ \\
\hline Mesenteric (g) & $7.6 \pm 0.9$ & $8.5 \pm 0.7$ & $8.2 \pm 0.5$ & $7.4 \pm 0.4$ \\
\hline LV and septum (mg/g of bw) & $2.2 \pm 0.08$ & $2.0 \pm 0.08$ & $2.1 \pm 0.06$ & $2.2 \pm 0.08$ \\
\hline $\mathrm{RV}(\mathrm{mg} / \mathrm{g}$ of bw) & $0.5 \pm 0.05$ & $0.4 \pm 0.03$ & $0.5 \pm 0.05$ & $0.5 \pm 0.02$ \\
\hline Liver (mg/g of bw) & $36.9 \pm 0.7$ & $36.8 \pm 0.6$ & $36.6 \pm 0.9$ & $37.5 \pm 3.0$ \\
\hline Spleen (mg/g of bw) & $2.8 \pm 0.1$ & $2.7 \pm 0.1$ & $2.7 \pm 0.1$ & $2.9 \pm 0.1$ \\
\hline Kidneys (mg/g of bw) & $7.6 \pm 0.2$ & $7.1 \pm 0.1$ & $8.2 \pm 0.2^{* \dagger}$ & $8.5 \pm 0.2^{* \dagger}$ \\
\hline 4-HNE (mmol/L) & $0.4 \pm 0.2$ & $10.4 \pm 0.9^{* \neq}$ & $3.6 \pm 0.8^{* \S}$ & $12.2 \pm 1.7^{* \neq}$ \\
\hline IL-6 (pg/mL) & $770.0 \pm 91.9$ & $194.3 \pm 31.5^{* \neq}$ & $620.0 \pm 91.7$ & $417.1 \pm 35.6^{*}$ \\
\hline $\mathrm{IL}-1 \beta(\mathrm{pg} / \mathrm{mL})$ & $105.4 \pm 13.6$ & $49.4 \pm 8.8^{*}$ & $67.2 \pm 12.0$ & $52.9 \pm 3.9^{*}$ \\
\hline Nitrate/Nitrite ( $\mu \mathrm{mol} / \mathrm{L})$ & $22.6 \pm 1.2$ & $33.6 \pm 2.7$ & $68.8 \pm 5.2^{*+\S}$ & $34.5 \pm 8.5$ \\
\hline Glucose (mmol/L) & $12.0 \pm 1.1$ & $11.9 \pm 1.0$ & $15.1 \pm 0.6^{* \dagger}$ & $12.4 \pm 1.0$ \\
\hline
\end{tabular}

Data expressed as Mean \pm SEM; $n=16$ for all groups. CON, control; PA, physical activity treated; HFHC, high-fat, high-carbohydrate fed; HFHC + PA, high-fat, high-carbohydrate fed and physical activity treated. ${ }^{*} \mathrm{P}<0.05$ vs $\mathrm{CON},{ }^{\dagger} \mathrm{P}<0.05$ vs $\mathrm{PA},{ }^{\ddagger} \mathrm{P}<0.05$ vs $\mathrm{HFHC},{ }^{\circledR} \mathrm{P}<0.05$ vs $\mathrm{HFHC}+\mathrm{PA}$. 
PA caused a significant increase $(\mathrm{P}<0.05)$ in lipid peroxidation, however a significant decrease $(\mathrm{P}<0.05)$ in circulating cytokine (IL-6 and IL-1 3 ) was also observed (Table 1).

Physical activity resulted in an enhanced aortic response to noradrenaline however the relaxation responses to $\mathrm{ACh}$ and $\mathrm{NaN}$ were unchanged (Figure 1A). Whilst not significant there was a trend that physical activity enhanced both the relaxation and contraction responses in bronchiole tissues (Figure 2).

Physical activity reduced ISO stimulated increases in heart rate from the right atria (Figure 3A) but did not alter any cardiac electrophysiological parameters (Table 2).

\section{Responses following HFHC feeding}

$\mathrm{HFHC}$ feeding did not increase body mass in the juvenileadolescent rats, however the diet did significantly increase retroperitoneal fat pad mass compared to the $\mathrm{CON}$ animals (Table 1). HFHC feeding also increased kidney mass but no other organ hypertrophy was observed (Table 1).

There was a significantly increased $\mathrm{kJ}$ intake in the HFHC groups compared to both standard chow fed animals (CON and PA) (Figure 4). Hypertension was induced by the HFHC diet with a significant increase of 9\% increase after 4 weeks, $14 \%$ after 8 weeks and $20 \%$ $(\mathrm{P}<0.05)$ in systolic blood pressure after 12 weeks of feeding (Figure 5).
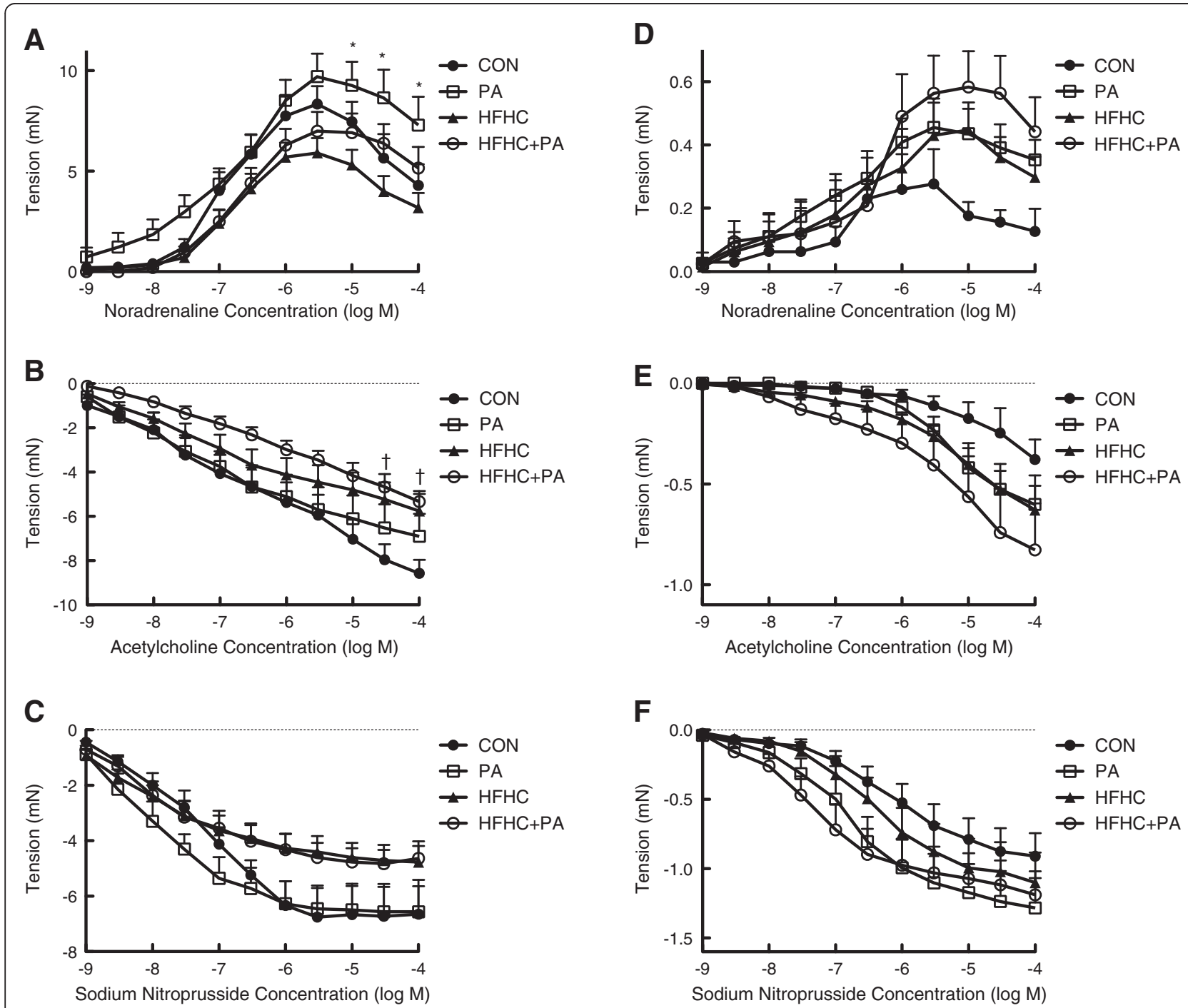

Figure 1 Vascular functional changes. A, Noradrenaline mediated contraction of the thoracic aorta. B, Endothelium-dependent relaxation by acetylcholine of noradrenaline pre-contracted thoracic aorta. C, Endothelium-independent relaxation by sodium nitroprusside of noradrenaline pre-contracted thoracic aorta. D, Noradrenaline mediated contraction of the pulmonary artery. E, Endothelium-dependent relaxation by acetylcholine of noradrenaline pre-contracted pulmonary artery. $\mathbf{F}$, Endothelium-independent relaxation by sodium nitroprusside of noradrenaline pre-contracted pulmonary artery. Data expressed as Mean \pm SEM; $n=16$ for all groups. ${ }^{*} \mathrm{P}<0.05 \mathrm{PA}$ vs HFHC, ${ }^{\dagger} \mathrm{P}<0.05 \mathrm{CON}$ vs HFHC $+\mathrm{PA}$. 

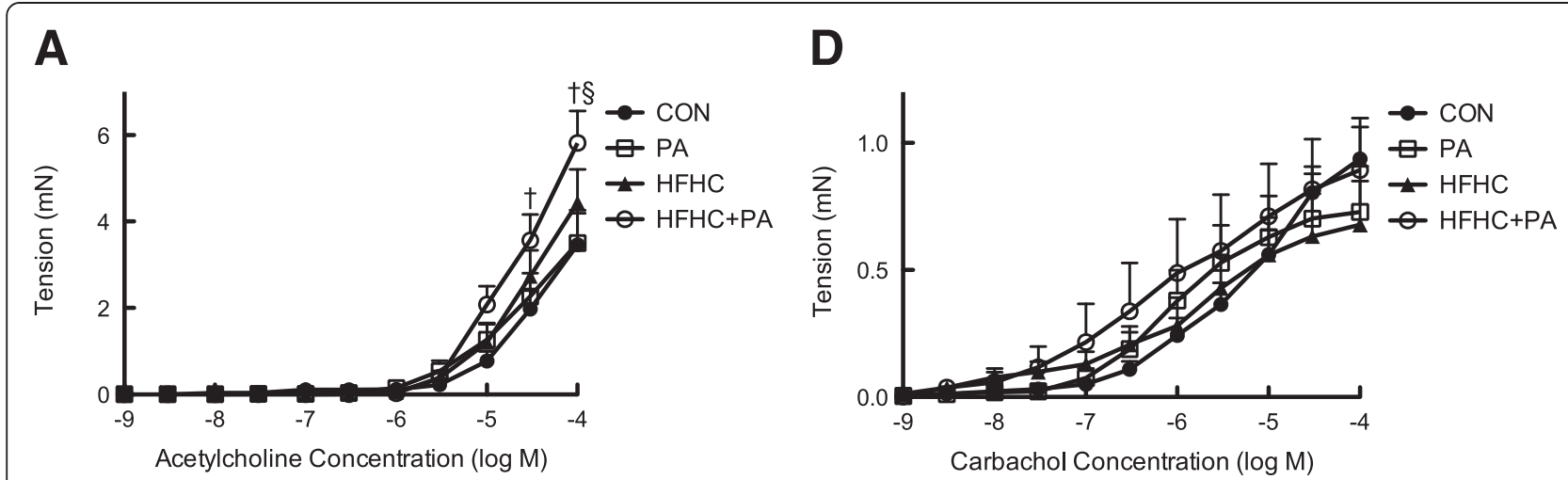

B

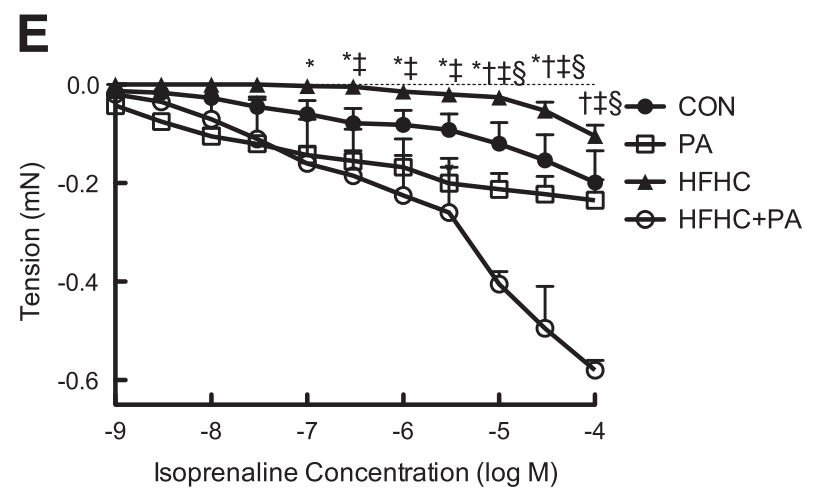

C

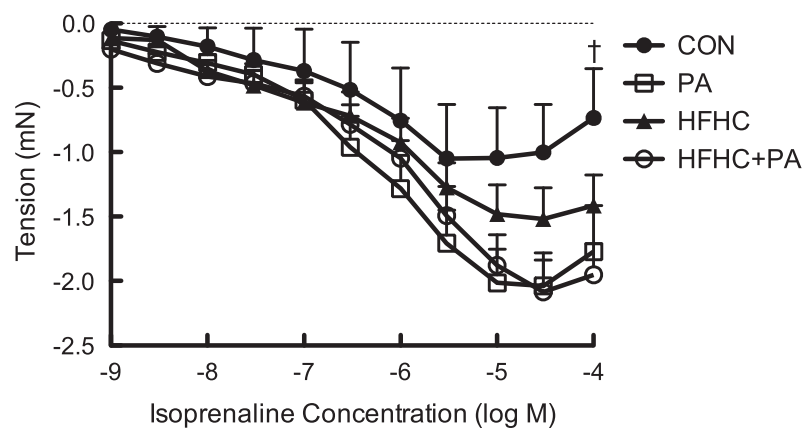

Figure 2 Small and large airway functional changes. A, Acetylcholine mediated contraction of the bronchioles. B, Serotonin mediated contraction of the bronchioles. C, Isoprenaline mediated relaxation acetylcholine pre-contracted bronchioles. D, Carbachol mediated contraction of the trachea of control. E, Isoprenaline mediated relaxation on carbachol pre-contracted trachea of control. Data expressed as Mean \pm SEM; $n=16$ for all groups. ${ }^{*} \mathrm{P}<0.05 \mathrm{PA}$ vs HFHC, ${ }^{\dagger} \mathrm{P}<0.05 \mathrm{CON}$ vs HFHC $+\mathrm{PA},{ }^{{ }^{\ddagger} \mathrm{P}}<0.05 \mathrm{HFHC}$ vs HFHC $+\mathrm{PA},{ }^{\S} \mathrm{P}<0.05 \mathrm{PA}$ vs HFHC $+\mathrm{PA}$.

HFHC also showed a significant increase $(\mathrm{P}<0.05)$ in 4-HNE values with no change in IL-6 and IL-1 $\beta$ levels (Table 1). The animals in this group were characterized by having significantly higher blood glucose values when compared to the CON experiments (Table 1).

The action potential duration in the papillary muscles were found to be significantly $(\mathrm{P}<0.05)$ prolonged in the HFHC group by $20 \%$ at $50 \%$ of repolarization and $30 \%$ at $90 \%$ of repolarization compared to the $\mathrm{CON}$ animals (Table 2).

HFHC feeding did not significantly alter $(\mathrm{P}>0.05)$ aortic (Figure 1) or respiratory (Figure 2) tissue responses but did show a significantly reduced right atrial response to ISO (Figure 3A).

\section{Responses following HFHC feeding and PA}

$\mathrm{HFHC}+\mathrm{PA}$ rats showed a significant decrease $(\mathrm{P}<0.05)$ in body mass compared to HFHC with a normalized retroperitoneal and subcutaneous fat pad mass (Table 1). However, physical activity was not able to normalize renal hypertrophy following HFHC feeding (HFHC + PA) (Table 1).

There was a significantly increased $\mathrm{kJ}$ intake in the HFHC + PA animals compared to both standard chow fed groups (CON and PA) (Figure 4). Systolic blood pressure 


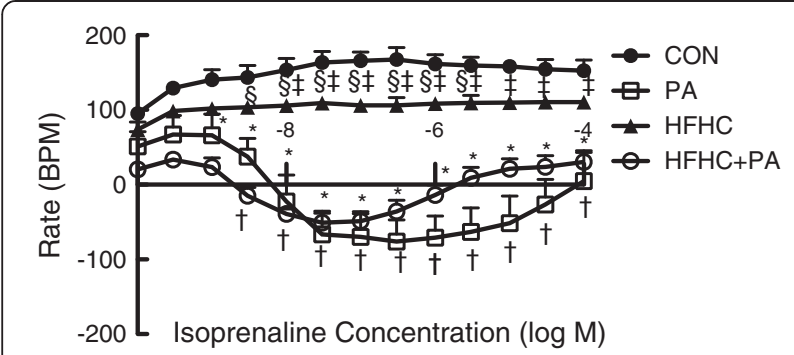

Figure 3 Isoprenaline mediated rate response of the right atria. Data expressed as Mean \pm SEM; $n=16$ for all groups. ${ }^{*} P<0.05$ CON vs HFHC + PA, ${ }^{\dagger} \mathrm{P}<0.05$ CON vs PA, ${ }^{\ddagger} \mathrm{P}<0.05 \mathrm{PA}$ vs HFHC, ${ }^{\circledR} \mathrm{P}<0.05$ $\mathrm{HFHC}$ vS HFHC + PA.

was significantly increased by $23 \%$ in the $\mathrm{HFHC}+\mathrm{PA}$ group in comparison to the CON group (Figure 5).

The HFHC + PA group showed significantly increased levels of 4-HNE, IL-6 and IL-1 $\beta$ levels compared to CON (Table 1). There was no significant difference in blood glucose levels between HFHC and $\mathrm{HFHC}+\mathrm{PA}$ rats or between HFHC + PA and CON (Table 1).

Physical activity was able to normalize the prolonged APD at 50 and $90 \%$ of repolarization observed in the HFHC fed animals (Table 2). Physical activity in the HFHC fed animals $(\mathrm{HFHC}+\mathrm{PA})$ decreased the atrial responses to the positive chronotropic agent ISO to a similar degree in PA group (Figure 3).

The HFHC + PA group showed exaggerated reaction to both relaxation and contraction response curves in the thoracic aorta and pulmonary arteries (Figure 2).

\section{Discussion and conclusions}

Moderate physical activity was able to prevent some of the maladaptive changes associated with chronic HFHC feeding in young rats, including, however it did not prevent an elevation in blood pressure. Non-significant trends in the data showed some improvement in vascular contractile responses to noradrenaline. Electrophysiological function at $50 \%$ and $90 \%$ of the action potential

Table 2 Resting membrane potential (RMP), action potential amplitude (AMP), action potential duration at $20 \%$ (ADP20), action potential duration at $50 \%$ (ADP50) and action potential duration at $90 \%$ (ADP90) of repolarization

\begin{tabular}{lllll}
\hline & CON & PA & HFHC & HFHC + PA \\
\hline RMP & $-69.5 \pm 1.7$ & $-64.1 \pm 1.7$ & $-67.1 \pm 1.2$ & $-62.4 \pm 1.8^{*}$ \\
APA & $66.2 \pm 2.8$ & $65.6 \pm 2.7$ & $68.5 \pm 2.1$ & $64.3 \pm 2.8$ \\
APD20 & $23.6 \pm 0.5$ & $24.5 \pm 0.3$ & $25.6 \pm 0.7$ & $23.9 \pm 0.6$ \\
APD50 & $32.2 \pm 1.4$ & $34.0 \pm 1.6$ & $38.6 \pm 1.4^{*}$ & $33.2 \pm 1.1^{\ddagger}$ \\
APD90 & $70.6 \pm 5.8$ & $77.2 \pm 0.4$ & $91.9 \pm 3.9^{*}$ & $77.9 \pm 4.2^{\ddagger}$ \\
\hline
\end{tabular}

Data expressed as Mean $\pm \mathrm{SEM} ; \mathrm{n}=16$ for all groups. ${ }^{*} \mathrm{P}<0.05$ vs $\mathrm{CON},{ }^{\dagger} \mathrm{P}<0.05$ vs PA, ${ }^{\ddagger} \mathrm{P}<0.05$ vs HFHC.

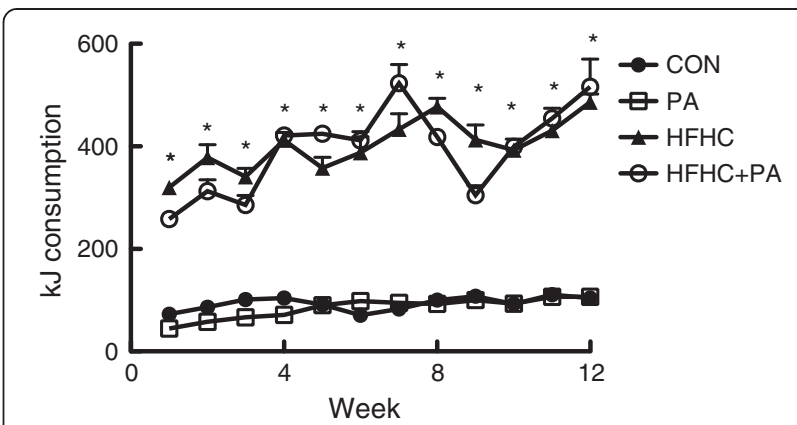

Figure $\mathbf{4} \mathbf{k J}$ intake. Data expressed as Mean $\pm \mathrm{SEM} ; \mathrm{n}=16$ for all groups. ${ }^{*} \mathrm{P}<0.05 \mathrm{CON}$ vs HFHC, HFHC + PA and PA vs HFHC, $\mathrm{HFHC}+\mathrm{PA}$.

duration was significantly increased by HFHC feeding, With the HFHC + PA group values not significantly different to the CON tissues. Moderate intensity physical activity in young healthy rats (PA group) produced the typically expected changes of a reduction in systemic inflammation and maintenance of body weight and systolic blood pressure similar to $\mathrm{CON}$ values. In contrast, juvenileadolescent normotensive rats fed a HFHC diet were mildly hyperglycemic, hypertensive and showed increased renal hypertrophy. Hearts from HFHC fed animals showed significantly prolonged action potentials with systemic increased lipid peroxidation as a common mediator of the metabolic syndrome. The presentation and degree of damage was not as large as reported in other studies, which may be due to the younger age of the animal model and the duration of HFHC feeding [32,36,37].

In this study, there was no significant gain in body mass in the HFHC group, despite an excess in kilojoules consumed compared to the CON animals. The amount of weight gain in the HFHC group observed in the current study is similar to a study that used a high fat diet over 12 weeks [38]. However, longer feeding periods (16 weeks) elucidated a larger weight gain response in HFHC fed animals [32]. Although not measured in the current study

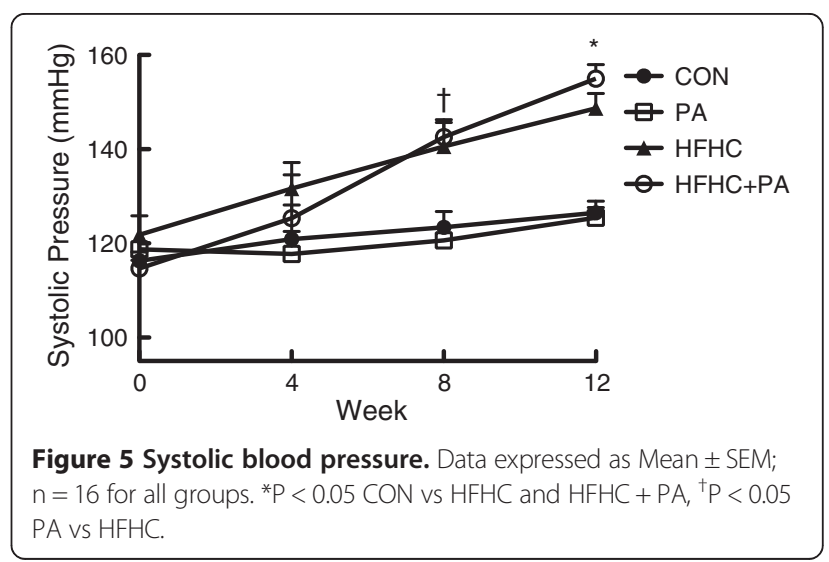


the weight gain may have been in relation to leptin resistance and appetite regulation. Leptin is an adipocytederived peptide, the production of which is increased in patients with obesity [39]. A recent study examined a model of diet-induced obesity and the response to leptin in several stages [36]. In the middle-stage (about 8 weeks), food intake reduced when the animal had an increase in leptin production and still retained central leptin sensitivity [36]. The animals seemed to control the rate of excess fat gain by significantly reducing food intake, however, despite the hypophagia, excess fat still accumulated at a reduced rate with apparent gains in energetic efficiency at least partially preventing this regulatory attempt [36]. However, in the later stages (4 months of high-fat feeding), the energy intake of the high-fat fed mice increased by $14.6 \%$ over the control fed animals, accompanied by a reduction of central leptin sensitivity [36]. Clearly, the increase in energy consumption of the HFHC diet in this study promoted changes in adipose deposition causing classical indicators of the metabolic syndrome, increased blood glucose and blood pressure, without excessive weight gain in these younger animals.

Although overall body mass was not significantly increased in the HFHC animals, there was a significant increase in retroperitoneal fat pad weight in the HFHC fed animals. This abdominal fat, has been shown to have a direct correlation with insulin resistance, and may be a better indicator of obesity related complications, than overall body mass $[25,40-44]$. HFHC has shown to cause adverse cardiovascular changes in rodent models as well as in humans $[32,37,45]$. HFHC feeding in humans, rats and pig models has been shown to cause adverse cardiovascular changes including coronary endothelial dysfunction, vascular oxidative stress, hypertension and cardiomyocyte hypertrophy [3]. Although overall body mass was not decreased in the HFHC + PA animals retroperitoneal and abdominal fat mass was reduced which may offer cardiometabolic benefits despite the lack of overall reduction in body mass. Although the program of physical activity was unable to significantly reduce overall body mass, retroperitoneal and abdominal, fat mass was reduced and clearly conferred cardiometabolic benefits [46,47]. It seems that overall body weight reduction may not be the most reliable indicator of the beneficial effects of physical activity [25].

Kidney hypertrophy was observed in the HFHC group, with no other significant changes in other organ masses. In this study, physical activity, was unable to reduce the increase in mass observed in kidney weight, caused by the HFHC diet. With hypertension thought to be a leading cause of renal disease, it is not surprising that many studies have tried to find the mechanism behind this effect. Studies showing that obesity-induced hypertension in dogs is associated with a shift of renal pressure natriuresis
[48] and that fructose-induced metabolic syndrome is also associated with renal disturbances characterized by renal hypertrophy $[49,50]$, arteriolopathy, glomerular hypertension, and cortical vasoconstriction [49]. The increase in kidney mass may potentially be due to the mild hypertension observed in the HFHC fed group.

Hypertension is one of the hallmarks of the metabolic syndrome and is induced by fructose and HFHC feeding $[32,51]$. The animal model of diet-induced obesity elicits an increase in systolic blood pressure in as little as four weeks $[52,53]$. In the present study, a significant increase in systolic BP was observed following 8 weeks of the HFHC diet and continued to increase until 12 weeks, similar to other studies $[3,52,53]$. One of the benefits of physical activity is a reduction in blood pressure [54,55], which was not observed in either of the physical activity groups in this study. This result is in disagreement with other findings [3]. One study showed that 13 weeks of physical activity caused a significant decrease in BP following diet-induced obesity in rats [3]. The length of physical activity treatment (8 weeks) in the current study may not have been long enough to attenuate the change caused by the HFHC diet. The speed and pace used in the current study in normal rats does induce improved left ventricular functional performance over 6-12 weeks period [30]. A significant decrease was not seen in systolic BP, potentially due to it not yet being stabilized, alternatively BP may have stabilized at a level that was not significantly lower. The findings in this study are supported by the isolated vessel studies, which showed no change in aortic dilation responses after physical activity. Other studies showing that cardiovascular damage and steady-state hypertension by diet-induced obesity was achieved only after the 16 weeks of feeding [32,53].

HFHC feeding showed a trend in decreasing inflammatory cytokine levels both in agreement [40,44] and contrast to previous studies $[21,32,37,42]$. These contrasting findings may be related to systemic inflammation as an expression of advanced obesity and insulin resistance which may not be present in animals treated for 12 weeks [44]. However physical activity significantly decreased IL-6 and IL-1 $\beta$ concentrations compared to the $\mathrm{CON}$ and $\mathrm{HFHC}$ fed groups. Animal studies have shown that cytokine expression is decreased in a physical activity model, and it was hypothesized that this may occur due to increased utilization of circulating fatty acids [42]. In addition, physical activity can reverse the increased levels of pro-inflammatory cytokine expression correlated to increased body mass, despite continued consumption of a high fat diet [42]. These changes persisted even though the high fat diet/physical activity mice had no significant decrease in body weight compared to the control group [42]. A recent study in a physical activity treated obese rat model found there was reduction in 
cardiomyocytes with inflammatory infiltrate in comparison to inactive obese rat model [56].

Oxidative stress originates in the mitochondria from reactive oxygen and reactive nitrogen species and has been linked to most of the key steps in the pathophysiology of CVD [57]. Our results showed a significant increase in this measure in the HFHC animals compared to the $\mathrm{CON}$ group. Interestingly, it was also to be significantly increased in our PA group and HFHC + PA group compared to our CON and HFHC group. While the HFHC diet increased lipid peroxidation, physical activity increased lipid peroxidation even further. Physical activity has been shown to induce oxidative stress partially through increased mitochondrial turnover, however with this is an adaptation or up regulation of oxidant defenses [58,59]. This increase in oxidative stress seen is only an issue when it is in response to other maladaptive processes like diet-induced obesity $[25,60]$.

The potential for cardiac arrhythmia development was increased in the young HFHC fed rats as demonstrated by a significant prolongation of the cardiac action potential. It has been found that in both obese and control rats that the four major ionic membrane currents responsible for controlling action potential duration are similar [61]. This suggests that prolonged action potential duration seen in HFHC animals was due to a different mechanism. One hypothesized theory is the absence of leptin in these animals on the ventricular sodium calcium exchange current. It has been shown that leptin receptor expression is down regulated in the hearts of obese animals compared to normal fed control animals [61]. Papillary muscles from the high fat diet fed rat hearts showed higher basal and maximum forces but a decreased recovery after a higher workload [62]. The underlying mechanism which links diet-induced obesity to the progression of mild cardiac hypertrophy is unclear [62]. It is hypothesized that obesity promotes pathological cardiac remodeling with left ventricular systolic dysfunction and an increase in myocardial stiffness, which, in turn, is probably related to afterload elevation and cardiac fibrosis [63]. Although physical activity was not able to completely reduce the prolonged action potential duration at both $50 \%$ and $90 \%$ following chronic HFHC feeding, it was able to significantly attenuate this increase. Changes seen in blood glucose, fat mass and inflammatory signaling were potential factors for this improvement but also improved calcium handling leading to increased cardiomyocyte contractility [30].

HFHC feeding was shown to cause a decreased response of the right atria to adrenergic stimulation. These changes have been hypothesized to be driven by ionic current changes [61]. Typically, expected findings occurred whereby exercise caused a decrease in heart rate response due to reduction in $\beta$-adrenergic receptors in the right atrium [64]. This also occurred during the $\mathrm{HFHC}+\mathrm{PA}$ group and was a healthy adaptation.

In conclusion, HFHC feeding in young rats induced a mild metabolic syndrome characterized by elevated BP and blood glucose, along with kidney hypertrophy, adipocytokine release, oxidative stress and cardiac action potential prolongation. Changes in vascular and respiratory tissues responses were minimal and linked to the juvenile-adolescent age of the experimental model. Physical activity in the young HFHC fed animals induced improvements in CVD risk by reducing components of the metabolic syndrome including a reduction in lipid peroxidation and cardiac action potential duration, which was believed to be mediated by a reduction in systemic inflammation.

\section{Competing interests}

There are no financial or non-financial competing interests to declare.

\section{Authors' contributions}

AvW was involved in conception and design, acquisition of data, analysis and interpretation of data, drafting and revising the manuscript. MD was involved in conception and design, drafting and revising the manuscript. FC was involved in conception and design and revising the manuscript. AF was involved in conception and design, acquisition of data, analysis and interpretation of data, drafting and revising the manuscript. All authors read and approved the final manuscript.

\section{Acknowledgments}

We thank Candice Pullen and Douglas Jackson for their time and effort in completing the laboratory work.

\section{Funding}

Scholarship and grant funding obtained from Institute of Health and Social Science Research (IHSSR), CQ University, Australia. This manuscript was supported by the CQUniversity Health CRN.

\section{Author details}

${ }^{1}$ Central Queensland University, Institute of Health and Social Science Research, Rockhampton, Queensland 4702, Australia. ${ }^{2}$ School of Medicine \& Public Health, Priority Research Centre in Physical Activity and Nutrition, The University of Newcastle, Newcastle, Australia. ${ }^{3}$ School of Medical and Applied Sciences, Central Queensland University, Rockhampton, Queensland 4702, Australia.

Received: 20 March 2014 Accepted: 23 June 2014 Published: 20 August 2014

\section{References}

1. Bocarsly M, Powell E, Avena N, Hoebel B: High-fructose corn syrup causes characteristics of obesity in rats: increased body weight, body fat and triglyceride levels. Pharmacol Biochem Behaviour 2010, 97:101-106.

2. Strauss R, Pollack H: Epidemic increase in childhood overweight, 1986-1998. J Am Med Assoc 2001, 286:2845-2848.

3. Pinheiro AR, Cunha AR, Aguila MB, Mandarim-de-Lacerda CA: Beneficial effects of physical exercise on hypertension and cardiovascular adverse remodeling of diet-induced obese rats. Nutr Metab Cardiovasc Dis 2007, 17:365-375

4. Carroll J, Zenebe W, Strange T: Cardiovascular function in a rat model of diet-induced obesity. Hypertension- J Am Heart Assoc 2006, 4865-72:65-72.

5. Raitakari OT, Juonala M, Viikari JS: Obesity in childhood and vascular changes in adulthood: insights into the Cardiovascular Risk in Young Finns Study. Int J Obes (Lond) 2005, 29(Suppl 2):S101-S104.

6. Erdos B, Kirichenko N, Whidden M, Basgut B, Woods M, Cudykier I, Tawil R, Scarpace PJ, Tumer N: Effect of age on high-fat diet-induced hypertension. Am J Physiol Heart Circ Physiol 2011, 301:H164-H172. 
7. Zhou Y-T, Grayburn P, Karim A, Shimabukuro M, Higa M, Baetens D, Orci L, Unger RH: Lipotoxic heart disease in obese rats: Implications for human obesity. Proc Natl Acad Sci U S A 2000, 97:1784-1789.

8. Erdos B, Cudykier I, Woods M, Basgut B, Whidden M, Tawil R, Cardounel AJ, Tümer N: Hypertensive effects of central angiotensin II infusion and restraint stress are reduced with age. J Hypertens 2010, 28:1298-1306. 1210.1097/HJH.1290b1013e328338a328075.

9. DeLorey D, Wyrick B, Babb T: Mild-to-moderate obesity: implications for respiratory mechanics at rest and during exercise in young men. Int J Obes 2005, 29:1039-1047.

10. Littleton SW: Impact of obesity on respiratory function. Respirology 2012, 17:43-49.

11. Parameswaran $K$, Todd DC, Soth M: Altered respiratory physiology in obesity. Candian Respiratory J 2006, 13:203-210.

12. Ritchie S, Connell J: The link between abdominal obesity, metabolic syndrome and cardiovascular disease. Nutrition, Metabolism \& Cardiovascular Disease 2007, 17:319-326.

13. Fantuzzi G: Adipose tissue, adipokines, and inflammation. Molecular Mechanisms in Allergy and Clinical Immunology 2005, 115:911-919.

14. Zou C, Shao J: Role of adipocytokines in obesity-associated insulin resistance. J Nutr Biochem 2008, 19:277-286.

15. Weiss R, Dziura J, Burgert TS, Tamborlane W, Taksali SE, Yeckel CW, Allen K, Lopes M, Savoye M, Morrison J, Sherwin RS, Caprio S: Obesity and the metabolic syndrome in children and adolescents. N Engl J Med 2004 350:2362-2374.

16. Kattan M, Kumar R, Bloomberg GR, Mitchell HE, Calatroni A, Gergen PJ, Kercsmar CM, Visness CM, Matsui EC, Steinbach SF, Szefler SJ, Sorkness CA, Morgan WJ, Teach SJ, Gan VN: Asthma control, adiposity, and adipokines among inner-city adolescents. J Allergy Clin Immunol 2010, 125:584-592.

17. Kim KW, Shin YH, Lee KE, Kim ES, Sohn MH, Kim K-E: Relationship between adipokines and manifestations of childhood asthma. Pediatr Allergy Immunol 2008, 19:535-540.

18. Caspersen CJ, Powell KE, Christenson GM: Physical activity, exercise, and physical fitness: definitions and distinctions for health-related research. Public Health Rep 1985, 100:126-131.

19. Marcell T, McAuley K, Traustadottir T, Reaven P: Exercise training is not associated with improved levels of C-reactive protein or adiponectin. Metabolism Clinical and Expermiental 2005, 54:533-541.

20. Thompson P, Buchner D, Pina I, Baladyy G, Williams M, Marcus B, Berra K, Blair S, Costa F, Franklin B, Fletcher G, Gordon N, Pate R, Rodriguez B, Yancey A, Wenger $\mathrm{N}$ : Exercise and physical activity on the prevention and treatment of atherosclerotic cardiovascuar disease: A statement from the Council on Clinical Cardiology (Subcommittee on excercise, rehabilitation and prevention). Circulation 2003, 107:3109-3116.

21. Nicklas B, Ambrosius W, Messier S, Miller G, Penninx B, Loeser R, Palla S, Bleecker E, Pahor M: Diet-induced weight loss, exercise, and chronic inflammation in older obese adults: a randomised controlled clinical trial. Am J Clin Nutr 2004, 79:544-551

22. Abramson $\mathrm{J}$, Vaccarino $\mathrm{V}$ : Relationship between physical activity and inflammation among apparently healthy middle-aged and older US adults. Arch Intern Med 2002, 162:1286-1292.

23. Fung T, Hu F, Yu J, Chu N-F, Speigelman D, Tofler G, Willett W, Rimm E: Leisure-time physical activity, television watching, and plasma biomarkers of obesity and cardiovascular disease risk. Am J Epidemiol 2000, 152:1171-1178.

24. Ziccardi P, Nappo F, Giugliano G, Esposito K, Marfella R, Cioffi M, D'Andrea F, Molinari A, Giuliano D: Reduction of inflammatory cytokine concentrations and improvement of the endothelial functions in obese women after weight loss over one year. Circulation 2002, 105:804-809.

25. Pellizzon M, Buison A, Ordiz F Jr, Santa Ana L, Jen KL: Effects of dietary fatty acids and exercise on body-weight regulation and metabolism in rats. Obes Res 2002, 10:947-955

26. Bizot JC, Chenault N, Houze B, Herpin A, David S, Pothion S, Trovero F: Methylphenidate reduces impulsive behaviour in juvenile Wistar rats, but not in adult Wistar, SHR and WKY rats. Psychopharmacol 2007 , 193:215-223.

27. Ting KN, Dunn WR, Davies DJ, Sugden D, Delagrange $P$, Guardiola-Lemaitre $B$, Scalbert E, Wilson VG: Studies on the vasoconstrictor action of melatonin and putative melatonin receptor ligands in the tail artery of juvenile Wistar rats. Br J Pharmacol 1997, 122:1299-1306.
28. Hendriksen I, Zuiderveld B, Kmeper G, Dick D: Effect of commuter cycling on physical performance of male and female employees. Med Sci Sports Exerc 2000, 32:505-510.

29. Oja P, Vuori I, Paronen O: Daily walking and cycling to work: their utility as health enhancing physical activity. Patient Educ Couns 1998, 33:S87-S94

30. Fenning A, Harrison G, Dwyer D, Rose'Meyer R, Brown L: Cardiac adaptation to endurance exercise in rats. Mol Cell Biochem 2003, 251:51-59.

31. Garber CE, Blissmer B, Deschenes M, Franklin B, Lamonte M, Lee I-M, Nieman D, Swain D: Quantity and Quality of Exercise for Developing and Maintaining Cardiorespiratory Musculoskeletal, and Neuromotor Firness in Apparently Healthy Adults: Guidance for Prescribing Exercise. Med Sci Sports Exerc 2011, 43:1334-1359

32. Poudyal H, Campbell F, Brown L: Olive leaf extract attenuates cardiac, hepatic, and metabolic changes in high carbohydrate-, high fat-fed rats. J Nutr 2010, 140:946-953.

33. Chicco A, Sparagna G, MCune S, Johnson C, Murphy R, Bolden D, Rees M, Gardner R, Moore R: Linoleate-rich high-fat diet decreases mortality in hypertensive heart failure rats compared with lard and low-fat diets. Hypertension- Journal of the American Heart Association 2008, 52:549-555.

34. Fenning A, Harrison G, Rose'Meyer R, Hoey A, Brown L: L-arginine attentuates cardiovascular impairment in DOCA-salt hypertensive rats. American Journal of Physiology- Heart and Circulation 2005, 289:H1408-H1416.

35. Coulson F, Jacoby D, Fryer A: Increased function of inhibitory neuronal M2 muscarinic receptors in trachea and ileum of diabetic rats. Bri J Pharmacol 2002, 135:1355-1362.

36. Lin S, Thomas TC, Storlien LH, Huang XF: Development of high fat diet-induced obesity and leptin resistance in C57BI/6J mice. Int J Obes Relat Metab Disord 2000, 24:639-646.

37. Sun Q, Yue P, Dieuliis J, Lumeng C, Kampfrath T, Mikolaj M, Cai Y, Ostrowski M, Lu B, Parthasarathy S, Brook R, Moffatt-Bruce S, Chen LC, Rajagopalan S: Ambient air pollution exaggerates adipose inflammation and insulin resistance in a mouse model of diet-induced obesity. Circulation 2009 119:538-546.

38. Buettner R, Parhofer KG, Woenckhaus M, Wrede CE, Kunz-Schughart LA, Scholmerich J, Bollheimer LC: Defining high-fat-diet rat models: metabolic and molecular effects of different fat types. J Mol Endocrinol 2006, 36:485-501

39. Abe Y, Ono K, Kawamura T, Wada H, Kita T, Shimatsu A, Hasegawa K: Leptin induces elongation of cardiac myocytes and causes eccentric left ventricular dilatation with compensation. Am J Physiol Heart Circ Physiol 2007, 292:H2387-H2396.

40. Abdullah MM, Riediger NN, Chen Q, Zhao Z, Azordegan N, Xu Z, Fischer G, Othman RA, Pierce GN, Tappia PS, Zou J, Moghadasian MH: Effects of long-term consumption of a high-fructose diet on conventional cardiovascular risk factors in Sprague-Dawley rats. Mol Cell Biochem 2009, 327:247-256

41. Boden G: Role of fatty acids in the pathogenesis of insulin resistance and NIDDM. Diabetes 1997, 46:3-10.

42. Bradley RL, Jeon JY, Liu FF, Maratos-Flier E: Voluntary exercise improves insulin sensitivity and adipose tissue inflammation in diet-induced obese mice. Am J Physiol Endocrinol Metabol 2008, 295:E586-E594.

43. Nieves D, Cnop M, Retzlaff B, Walden C, Brunzell J, Knopp R, Kahn S: The atherogenic lipoprotein profile associated with obesity and insulin resistance is largely attributed to intra-abdominal fat. Diabetes 2003 52:172-179.

44. Galili O, Versari D, Sattler KJ, Olson ML, Mannheim D, McConnell JP, Chade $A R$, Lerman LO, Lerman A: Early experimental obesity is associated with coronary endothelial dysfunction and oxidative stress. Am J Physiol Heart Circ Physiol 2007, 292:H904-H911.

45. Sharma N, Okere I, Duda M, Chess D, O'Shea K, Stanley W: Potential impact of carbohydrate and fat intake on pathological left ventricular hypertrophy. Cardiovasc Res 2007, 73:257-268.

46. Purnell J, Kahn S, ALbers J, Nevin D, Brunzell J, Schwartz R: Effect of weight loss with reduction of intr-abdominal fat in lipid metabolism in older men. J Clin Endocrinol Metabolism 2000, 85:977-982.

47. Rader DJ: Effect of insulin resistance, dyslipidemia, and intra-abdominal adiposity on the development of cardiovascular disease and diabetes mellitus. Am J Med 2007, 120:S12-S18.

48. Hall JE, Brands MW, Dixon WN Jr: MJS: Obesity-induced hypertension Renal function and systemic hemodynamics. Hypertension 1993, 22:292-299. 
49. Sánchez-Lozada LG, Tapia E, Jiménez A, Bautista P, Cristóbal M, Nepomuceno T, Soto V, Ávila-Casado C, Nakagawa T, Johnson RJ, Herrera-Acosta J, Franco M: Fructose-induced metabolic syndrome is associated with glomerular hypertension and renal microvascular damage in rats. Am J Physiol Ren Physiol 2007, 292:F423-F429.

50. Vora JP, Dolben J, Dean JD, Thomas D, Williams JD, Owens DR, Peters JR: Renal hemodynamics in newly presenting non-insulin dependent diabetes mellitus. Kidney Int 1992, 41:829-835.

51. Singh AK, Amlal H, Haas PJ, Dringenberg U, Fussell S, Barone SL, Engelhardt $R$, Zuo J, Seidler U, Soleimani M: Fructose-induced hypertension: essential role of chloride and fructose absorbing transporters PAT1 and Glut5. Kidney Int 2008, 74:438-447.

52. Katakam PVG, Ujhelyi MR, Hoenig ME, Miller AW: :öijendothelial dysfunction precedes hypertension in diet-induced insulin resistance. Am J Physiol Regul Integr Comp Physiol 1998, 275:R788-R792.

53. Iyer A, Brown L: Fermented wheat germ extract (avemar) in the treatment of cardiac remodeling and metabolic symptoms in rats. Evidence-based complementary and alternative medicine: eCAM 2011, 2011:508957.

54. Veras-Silva AS, Mattos KC, Gava NS, Brum PC, Negrao CE, Krieger EM: Low-intensity exercise training decreases cardiac output and hypertension in spontaneously hypertensive rats. Am J Physiol 1997, 273:H2627-H2631.

55. Yen MH, Yang JH, Sheu JR, Lee YM, Ding YA: Chronic exercise enhances endothelium-mediated dilation in spontaneously hypertensive rats. Life Sci 1995, 57:2205-2213.

56. Bunker AK, Arce-Esquivel AA, Rector RS, Booth FW, Ibdah JA, Laughlin MH: Physical activity maintains aortic endothelium-dependent relaxation in the obese type 2 diabetic OLETF rat. Am J Physiol Heart Circ Physiol 2010, 298:H1889-H1901.

57. Pashkow FJ: Oxidative Stress and Inflammation in Heart Disease: Do Antioxidants Have a Role in Treatment and/or Prevention? Int J Inflam 2011, 2011:514623.

58. Davies KJ, Quintanilha AT, Brooks GA, Packer L: Free radicals and tissue damage produced by exercise. Biochem Biophys Res Commun 1982, 107:1198-1205.

59. Brady PS, Brady LJ, Ullrey DE: Selenium, vitamin E and the response to swimming stress in the rat. J Nutr 1979, 109:1103-1109.

60. Minami A, Ishimura N, Harada N, Sakamoto S, Niwa Y, Nakaya Y: Exercise training improves acetylcholine-induced endothelium-dependent hyperpolarization in type 2 diabetic rats, Otsuka Long-Evans Tokushima fatty rats. Atherosclerosis 2002, 162:85-92.

61. Ricci E, Smallwood S, Chouabe C, Mertani HC, Raccurt M, Morel G, Bonvallet R: Electrophysiological characterization of left ventricular myocytes from obese Sprague-Dawley rat. Obesity (Silver Spring) 2006, 14:778-786.

62. Ouwens DM, Boer C, Fodor M, Galan P, Heine RJ, Maassen JA, Diamant M: Cardiac dysfunction induced by high-fat diet is associated with altered myocardial insulin signalling in rats. Diabetologia 2005, 48:1229-1237.

63. Leopoldo AS, Sugizaki MM, Lima-Leopoldo AP, do Nascimento AF, Luvizotto Rde A, de Campos DH, Okoshi K, Dal Pai-Silva M, Padovani CR, Cicogna AC: Cardiac remodeling in a rat model of diet-induced obesity. Can J Cardiol 2010, 26:423-429.

64. Hammond HK, White FC, Brunton LL, Longhurst JC: Association of decreased myocardial beta-receptors and chronotropic response to isoproterenol and exercise in pigs following chronic dynamic exercise. Circulation Res 1987, 60:720-726

doi:10.1186/2052-9538-1-11

Cite this article as: van Waveren et al:: Moderate intensity physical activity prevents increased blood glucose concentrations, fat pad deposition and cardiac action potential prolongation following diet-induced obesity in a juvenile-adolescent rat model. BMC Obesity 2014 1:11

\section{Submit your next manuscript to BioMed Central and take full advantage of:}

- Convenient online submission

- Thorough peer review

- No space constraints or color figure charges

- Immediate publication on acceptance

- Inclusion in PubMed, CAS, Scopus and Google Scholar

- Research which is freely available for redistribution

Submit your manuscript at www.biomedcentral.com/submit
C Biomed Central 